\title{
A Study on Public Awareness \& Media Coverage of Nuclear Energy Issues in India
}

\section{S. Arulchelvan, Anna University, India.}

\begin{abstract}
Nuclear energy is a controversial and sensitive subject among the public, because it strongly relates public health and safety. Due to this mass media is handling this subject in a diverse manner thereby it creates strong impact among the people. Public's acceptance and support to the nuclear energy is also preoccupied. The aim of this study is focused to find out the awareness level about the nuclear energy among the public and the media coverage. Survey, content analysis, interview methods were used to gather the fact. The results show that the awareness on nuclear energy issues is less among the public. Indian newspapers are publishing minimum articles on nuclear energy and it is not getting priority except emergencies. Both journalists and nuclear plant authorities have many deficits. The study recommends regular interaction with media, providing needy information and training and often visit to the nuclear plants could bring a tremendous change.
\end{abstract}

Keywords: Nuclear Issues, Public Perception, Energy, Media \& Nuclear Issues, News Coverage 


\section{Introduction}

In the whole range of topics regarding our impact on nature, a major discussion of the last decades and now has been use of nuclear energy. This subject is very sensitive among the general public because it strongly relates public health and safety. Due to this kind of sensitivity, the mass media is handling the subject in a diverse manner. Nowadays the environmental movements are increased and they play an active role against nuclear energy. The problem is not only on these opinions that are disseminated by the mass media but also may be due to unclear statements and opinions. And no expert or an authority is ready to explain the facts in a proper manner and not trying to take away the fear of public.

But the same time, most of the developed countries have established a number of nuclear power plants and research stations and they are self-dependent for future generations. Experts advised that nuclear energy production is one of the safest way and they list out number of successful nuclear power plants across the world.

According to the policies many world countries, nuclear energy is very important for the present world and future generation and this is the only one alternative for the conventional energy production like hydrothermal energy and coal energy etc. But the nuclear energy production is a controversial topic, especially in the developing countries. Proponents call it is the most viable/best alternative, currently available resource for meeting the world's growing energy needs, while protagonists say that the nuclear waste has created greatest problem to the world.

Regarding India, nuclear energy is the fourth-largest source of electricity after thermal, hydro and renewable sources of electricity. India now envisage by increasing the contribution of nuclear energy to overall electricity generation capacity from $4.2 \%$ to $9 \%$ within 25 years. India has 17 nuclear power plants in operation, generating 4,120 MW while 6 others are under construction and expected to generate an additional 3,160 MW.

Among the various sources, nuclear energy is the cost effective and more productive one for energy needs. Nuclear stations are very useful not only for energy production, but also for medical treatments, medicines, research and other productive measures. But the same time, most of the people fear about the nuclear energy. Some of the environmental groups and 
voluntary organizations are also opposing the nuclear energy power plants. Nuclear scientists say this is due to the less awareness about the nuclear energy. Mass media is one of the vital tools in creating the awareness to large masses. But most journalists do not appreciate the nuclear energy due to lack of information.

\section{Goal of the Study}

According to the various stake holders of the nuclear energy, there is a larger gap between Government/ Nuclear Agencies, Mass Media and Public. Due to this gap, the problem is arising and the public is getting afraid. Government and Nuclear Agencies are not using the mass media in awareness creation to avoid the fear among the public in effective manner. Mass media is not giving importance to the nuclear energy news. Media has a perfect job; the essential activity of the media is conveying facts. The effect of the mass media is not restricted to individuals but it extends to whole. Hence, there is a need to study the nuclear energy issues and its perception among the public and media coverage in Indian context. This study is structured to find out the problems, gaps regarding to nuclear issues, media, public and experts. The major aim of the study is to find out the awareness level/perception about the nuclear energy issues among the public and how the media represent the nuclear issues. The major objectives of the research are: To know the awareness level and perception of nuclear energy and related issues among the public; to analyze the nuclear issues published in the newspapers; to know the opinion about the nuclear issues of the nuclear power plant constructions and media experts.

\section{Review of Literature}

Nuclear energy and related issues is still a controversial subject in the world countries either developed or developing one. Therefore, creating awareness and understanding about the nuclear issues and eliminating fear among the public are important. According to NPT, (1995), “importance of openness, transparency and public information, which must ensure that an unbiased assessment of the safety performance of nuclear facilities can be, developed. To enhance public awareness/ understanding on nuclear safety, radiation protection and waste management is highly important. Many experts are believing that nuclear energy is important for humanbeing. It is useful not only for electricity but also health, medicine, agriculture, food, and various technologies. NAS, (1956) emphasized that exposure to the radiation is 
limited to levels of which the genetics committee believes reasonable; there should be practically no pathological effects. It can enhance man's food supply rather than damaging.

Countries having more energy production could help industrialization, employment, food production and overall development. Electricity is an absolute necessity for development and quality of life. More than half of the world's population has not developed adequate supplies (Olds, 1997). But at the same time huge number of people has been led to believe that nuclear energy is not needed. It is unsafe, poses an unfathomable waste disposal problem and not good for environment. None of these is true. Nuclear energy is clean and safe (Beatty, 1997). Nuclear energy is seen as a certain imperative the only practical, economical, large-scale source of electricity that does not pollute or produce greenhouse gases (Dutton, 1997).

According to Boyar, (1997), people would live longer and healthier if they received a little more radiation. But, the news and entertainment media have made politically correct the idea that radiation exposure is harmful at all levels. Voiland, (2003), states that 42 nations have approved the use of food treated by radiation. Irradiation of foodstuffs markedly extends the shelf life and "freshness" period of fruits, vegetables, poultry, seafood and meat. Not only that, over 0.44 million jobs exist in the nuclear energy industry. Frost (2005) and Beatty (2009), says that environmentalists are reconsidering their opposition on nuclear plants. Nuclear energy does not contribute to global warming not release toxic chemicals.

Nuclear energy offers the possibility of large quantities of base load for electricity that is cleaner than coal, more secure than gas, and more reliable than wind. A British poll showed $30 \%$ of the population against nuclear energy, compared with $60 \%$ three years ago. An American poll in March this year showed 50\% in favor of expanding nuclear energy, up from $44 \%$ in 2001 (Beatty, 2009). Nuclear community has failed to help people understand the real facts. Most people are only dimly aware that the earth's reserves of oil and natural gas are strictly limited. Still fewer know that fast reactors could safely provide all the world's energy needs for thousands of years (Boyar, 2010).

Opposition to nuclear energy is based on irrational fear fed by Hollywood-style fiction, the Green lobbies and the media. Marsh \& Stanford, (2006), provide a new way to export nuclear energy to developing nations. Self-contained reactors called "nuclear batteries," would be available in a variety of sizes. Sealed and fail-safe, they would be manufactured at a central 
location and rented to nations. At the end the exhausted reactor cores, still sealed, would be traded for rejuvenated ones.

Public's support to the nuclear energy is increasing now a days. Bisconti, (2006) finds from a new national survey, nearly seven in 10 Americans favour of nuclear energy and support building new reactors. Graham, (2010) had done a review of 175 survey questions which measure American public awareness and knowledge of nuclear issues from 1945 through 1987. Level and rate of diffusion of nuclear awareness varies greatly, there seems to be a limit to the number of people who learn of nuclear issues. Nuclear Perception, (2011), pointed some vital developments from the Euro barometers polls. It shows that $8 \%$ favored to nuclear energy, $20 \%$ were for new constructions, while $37 \%$ opposed. France, the most pro-nuclear energy country (75\%), but supports the production of nuclear plants by only $25 \%$. Generally, as time passes, support for nuclear energy increases. In the UK, $(20 \%$ nuclear energy) the government rallied the public to support nuclear energy through transparency and trust initiatives. However, public opinion is typically based on what people have experienced through their limited connection with the limited media. Trust initiatives involving transparency and awareness in the UK, can make such a big difference in public opinion. The trend that more informed people favor nuclear energy is not coincidence.

Indian scenario is also shows some important issues. According to Deolalikar (2008) health safety in nuclear energy plants is a very important topic and it is necessary to dissipate correct information to the public at large. Ramamurthy (February 26, 2009) said, nuclear energy had wide applications in the fields of agriculture and healthcare also, besides meeting the energy requirements. Atomic energy wants to create public awareness and dispel fears about nuclear energy among people. Singh, (2009) provides some key advantages. In the nuclear energy production, one kilogram of uranium produced energy equivalent to 10 lakh $\mathrm{kg}$ of coal. Further, the amount of waste generated was just a fraction compared to thermal plants.

Mass media is one of the controversial partner to the nuclear issues. It is handling the nuclear subject in a different manner. Charman, (2001) reveals that, in 1985 The Forbes magazine's cover story declared 'U.S. nuclear energy the largest managerial disaster in business history'. But now, nuclear energy is being widely reported in the mainstream media as not only the cheapest, but also as a clean and environmental friendly. NBC Nightly News said that 'two 
decades ago, fear nearly crippled the industry. Now those fears have receded, and nuclear energy could play a huge role.' Kincaid, (2005) has criticized media's role in nuclear energy. America hasn't built any nuclear plants because of the impact of Jane Fonda's 1979 film, The China Syndrome, about an accident in a nuclear energy plant. Media coverage of the actual nuclear accident at Pennsylvania's Three Mile Island plant that same year also contributed, of course. But the release of radiation from that mishap was contained, and there were no injuries or deaths, only mental distress caused by the media coverage. The Hollywood version of the truth is that nuclear energy is bad.

It is not surprising that the mainstream media does not cover the nuclear issue fairly (Moore, 2009). The author says that, mainstream corporate media clearly has its bias, best evidenced in the issues that it doesn't cover, but also in its role as corporate mouthpiece, and in its focus on trivia and sensationalism. Bell, (2010) speaks that media reporting of the nuclear component of Japan's earthquake and Tsunami tragedy has lacked objectivity and proportionality. It is compounding already high public anxiety and confusion. Excessive attention has been directed to hypothetical radiation dangers relative to the enormous scale of broader havoc wrought by those incredible disasters. Realistic risks have often been exaggerated by poorly informed reporters, along with alarmist agenda-driven commentators presented as experts.

The future of nuclear on the top of the agenda with the Fukushima accident, the nuclear energy debate is back in the mainstream media. Before March 11, the nuclear renaissance and nuclear energy as a source of clean energy have only been a peripheral topic (Jones, 2011). News media have struggled to sort through confusing and often conflicting, information about damage to the crippled plant and its threat to public safety in Japan (Joseph, 2011).

To avoid the underutilization of mass media, better usage, creating public understanding and getting support is highly important for nuclear energy. For the purpose, to educate media personnel about the workings of nuclear energy facilities so they can better interpret emergency situations to the public (Berry, Jones, \& Energys, 1999). The authors said, this education should occur before a nuclear emergency takes place and should contribute toward development of a shared language free of technical jargon. Journalists must learn to accept imprecise and maybe answers from nuclear technicians and to report them responsibly. They 
are also obliged to put developments in an emergency situation into context for the benefit of a concerned and anxious public. Arulchelvan (2010) opined that, science and technology news is very little attended by the media. This worst situation has been developed by various reasons, one being researchers/scientists are not open to media. They are hardly accessible to journalist and using technical language. It will affect the public's scientific awareness about new innovation and developments. There is a lack of dedicated $\&$ trained science reporters in the media. The scenario can be changed by recruiting special correspondents, providing training to the existing journalists and change of experts' attitude.

Effective communication is very important for achieving the goal, especially in the nuclear issues. It creates large dissemination of information, better reach and best understanding among the public about the issues. Experst quoted many worst situations arised due to the bad communication strategies. Abalkina \& Melikhova, (2006) mentioned that the legislative features, short democratic experience with modest communication are among most substantial barriers to effective public communication on nuclear issues in Russia. In the former USSR environmental issues emerged on the agenda in late 1980s and became the platform for many protest movements. It was also the time when Chernobyl theme began to be heavily exploited. Nevertheless, one cannot conclude that general public is always in opposition to the nuclear industry in Russia. Public opinion polls show that people are in favor of nuclear energy if the region experiences energy shortages.

According to Fischhoff, (2009), if the nuclear energy industry is to be seen as a responsible partner with the public, it must change the way it communicates. Management must think of its external communications as key parts of the firm's activity. Perko, (2011), emphasized that communication is one of the most important challenges in emergency management. In the early phase, communication increases awareness and understanding of protective actions and improves the response. In the medium and long term, risk communication can facilitate the remediation process and return to normal life. Mass media play a central role in risk communication. The nuclear accident in Japan has predictably induced enormous media coverage. Proper and transparent communication will strengthen trust in the nuclear energy.

According to Ropeik, (2011) the radiation crisis in Japan worsens for many reasons: one that we've heard about, one that we haven't but which may in the end do far more harm. The 
Japanese government, and the company in charge of the crippled nuclear complex, are struggling with their risk and crisis communications, and their missteps are fueling mistrust and anger, which magnifies fear and stress, which may do more health damage than the radiation itself. The nuclear industry has done a great communications job in getting its messages across to decision makers over the last decade (Dewhurst, 2011). But in the wake of the Fukushima disaster and in the midst of a global recession, the industry has to be more proactive in stating its case in the years ahead. A sustained, proactive communication campaign must remain at the forefront of the industry's mind if the world is to meet its rising demand for secure and clean energy.

\section{Methodology}

Survey, content analysis and interview methods were used for gathering data and facts. The survey was conducted during the month of February 2011 among the respondents from various cross sections of people. The sample population is from Chennai and Kalpakkam area. Chennai is the capital city of Tamil Nadu state and Kalpakkam, is an important township which consist Madras Atomic Energy Station which is $80 \mathrm{~km}$ away from Chennai. The sampling size was 300 and simple random sampling technique was followed. A questionnaire was used to gather data. The questionnaire consist questions on personal profile of the respondents, newspaper reading habits, their awareness level about nuclear energy and related issues. Content analysis was done in two phases from two different periods. One is non-peak season mean there is no emergency, important issues and problems related to the nuclear issues (January, February and March of 2010). Another period is peak news season mean after the Fukushima Energy Plant Accident due to Tsunami (April, May and June of 2011). Hence, the study could get excellent data about the publication of nuclear issues from the newspapers. The content analysis was used as it can help to understand the amount of coverage given by the popular newspapers Daily Thanthi, Dinakaran (both are Tamil language newspaper) and The Hindu (English newspaper) to the nuclear energy and its related issues. Total number of news stories on nuclear energy issues, the tone of the story, placement, visibility, size, etc. were analyzed. Interview method is also used for gathering some facts, opinions about the nuclear issues, media portrayal, awareness, etc. Journalists, atomic energy plant authorities, nuclear and media experts were interviewed for this purpose. 


\section{Results and Discussion}

The results of the survey, content analysis and in-depth interview are presented and discussed here.

\section{Respondent's Profile}

This survey has 300 respondents; they were chosen by simple random sampling technique. The respondents were from Chennai (60\%) and Kalpakkam (40\%). Among them $43 \%$ people are employees from government and private sectors, $36 \%$ are students and $21 \%$ are small entrepreneurs, housewives and elders. The respondents have different age group and all responded eagerly.

\section{Newspaper Reading and Respondents}

Awareness is directly related with the access and usage of mass media, because media provides a lot of information on day-to-day basis. Newspapers are still a dominant and convenient medium for the public, especially developing countries. The survey found that, almost all of the respondents are reading different dailies in Tamil and English, but mostly they prefer Tamil dailies. Among the respondents Daily Thanthi had highest readership followed by Dinakaran, both are Tamil newspapers $45 \%$ and $29 \%$ respectively. The Hindu English newspaper was the next in this list have $21 \%$ of readership. Other newspapers Dinamani (14\%), Dinamalar (12\%) and Indian Express \& Times of India have each 9\%.

\section{Awareness about Nuclear Energy Uses in Various Sectors}

Nuclear energy is one of the important issues in the last few years. Most of the governments are trying to establish new atomic energy plants. At the same time they are getting opposed from various groups of people like public, NGOs, experts, environmentalists, etc. General public also is getting aware about these issues. In this study, the data reveals that about $73 \%$ of respondents are aware that the nuclear energy is useful for generating electricity. Regarding to other uses of nuclear energy only $39 \%$ of respondents are aware that nuclear energy is useful for medicine, technology, weapons. $61 \%$ of respondents are not informed.

\section{Safety of Nuclear Energy \& Respondents}

A common mentality is that the nuclear energy is not safe, whether they know about the nuclear energy and technology or not. Especially countries like India, it is a major issue. So, 
in this research to confirm the mentality of the common people a vital question was asked "is nuclear energy safe or not ". It is found that only $26 \%$ of the respondents are felt that nuclear energy is safe, $74 \%$ respondents felt that it is not safe, it is dangerous. This is because of the fact that they are not properly informed about the radiation and safety measures in the atomic energy stations.

\section{Awareness about Nuclear Deal}

The Indo-American nuclear deal was one of the important issues in India. It is a civil nuclear agreement between India and America (US). It was signed in the 2008. Many political parties, media, voluntary organizations, groups were opposed the agreement. Mass media also gave more space for this issue at the time. Whether public know the issue or not? It is an important question at this time. The data shows that only 30 percent of the people are aware on nuclear deal between India and America, while 27\% just heard of it and 43\% do not know anything about the nuclear deal.

\section{Support to Nuclear Energy Plants}

Regarding to nuclear issues, still public has a confused state of mind. From the data a contradiction has come out. Even though the public is afraid of the safety of nuclear plants, $75 \%$ of the respondents welcome nuclear energy plant India. They opined that nuclear energy supply can boost industries and provides more employment. Another $16 \%$ says that nuclear energy is not good for future and safety of the public. Other $9 \%$ of respondents are not able to decide whether welcome it or not, as they are not clear about the importance and impact of nuclear energy.

\section{Feeling about Living in and Around the Nuclear Energy Plant Area}

Even though the people have fear about the nuclear plants, many people are living in villages around the plants. Data shows that $53 \%$ of the respondents are frightened to live around nuclear energy plant; even some of them are living $80 \mathrm{~km}$ away from the plant. And $22 \%$ of respondents feel comfortable in living. $25 \%$ of people feel they are safe in Kalpakkam nuclear energy plant area as there have not been any damages or history of serious accident happened in Kalpakkam even during dangerous natural calamity like Tsunami. 


\section{Awareness about the Protection Arrangements of Energy Plants and Emergency}

Nuclear energy plants are built up with good protection and they are ready with safety measures at the time of emergency. A limited segment of the people is aware of it. Among the respondents $57 \%$ are not aware of protection arrangements in nuclear energy plant or its radiation effects and emergency. $21 \%$ are says that they do not know the protection arrangements, but know the safety measure during emergency. Their knowledge about safety measures during the emergency is also very poor. Proper measures are not fully conveyed to them. Only $22 \%$ of respondents are aware of protection arrangements in nuclear energy plant or its radiation effects and emergency. But, they are agreed that we do not know the entire information.

\section{Newspapers Content on Nuclear Issues and Respondents Opinion}

There is an accusation that not much news on nuclear plants and related issues. Among the respondents who read newspaper, 22\% responded they do not get enough information about the nuclear issues, while $10 \%$ felt that they are confused after reading the news articles. $22 \%$ of respondents said that after reading the news they are getting the sense of fear especially during some other emergencies like Tsunami, etc. $22 \%$ of the respondents can't follow the news articles while $5 \%$ of people feel it's unrelated to them in their day to day life.

\section{Expectation from Media by the Respondents}

Data shows that $43 \%$ of respondents felt that images play a vital role to grab attention and trust into the news story. This is may be well know truth that pictures can tell much information and make trust among the public'. $38 \%$ is felt that more articles related to nuclear issues have to be covered to keep the people well informed about the future energy. $19 \%$ of the people requested that the news articles should be in simpler words and sentences in order to follow and understand easily.

\section{Barriers for Reading Articles Related to Nuclear Energy}

Getting attracted to read a news article has many barriers. 55\% of the respondents say that, proper visibility and space is not provided for the nuclear energy articles. $40 \%$ is accusing that use of scientific terminology is a barrier to follow up these articles. Rest $5 \%$ feels, the news item are covered in such a manner that there is no connectivity with their day to day activities, can't relate it to their life. So, they lost their interest in reading the news. 


\section{Trust of News and Respondents}

During emergencies usually general public depends on mass media for getting information. Among the respondents $56 \%$ says that they believe/trust the news published by the newspapers during any emergency or crisis situation regarding to nuclear energy. $44 \%$ says that we believe word of mouth from any officials, friends and neighbors, we do not believe newspapers. This is because of their previous experiences by the newspapers and reality. They need proper and unbiased information which is of clear to understand, making use of graph/pictures is essential part of news article coverage to make it meaningful purpose. Quoting with the trustworthy persons from the atomic plants, specialization is also needed for the publication of these issues.

\section{News Stories related to Nuclear Energy Issues Published by Daily Thanthi}

The Daily Thanthi newspaper has published 7 news articles during the non-peak season (average 2.33 per month) and 34 news articles during the peak season (11.33 per month). In the non-peak season no article is published in the first page or main page. All the articles placed in the district, state pages. These news articles are not appearing in the visible pages. The placement also is not good. Most of them are announcement in nature; the articles are issued in the form of press release by the atomic plant authorities. There is no news in negative or neutral view. No news has picture, but all are reported by the newspaper's own source. But during the peak season this trend is completely changed. Significant numbers of articles are published in the main page and number of articles is also more. The size and placement of the news got some more importance. Many articles are with neutral and negative portrayal. It shows that many articles are gathered by the journalists, and are not issued by the authorities. They had published articles about the dangers of the nuclear plants, radiation and fear of the public. Some of the articles have pictures; hence they are more attractive and show its importance. About $50 \%$ of the news articles from own source and remaining from news agencies.

\section{News Stories related to Nuclear Energy Issues Published by Dinakaran}

The Dinakaran newspaper has also followed the same trend in publishing of nuclear related issues. During the non-peak season the newspaper published very less number ( 7 articles with average of 2.33 per month) and in the peak season this number is high (30 articles with average of 10 per month). No news is published in the main page during the non-peak season; 
all are placed in state, district, city pages with small sizes. Most of the news articles are announcement based and remaining are supportive to the plant. But regarding to pictures, no one is found and most of the news from own source. During the peak season this trend is entirely altered. Many articles published in the main page and nation page with larger sizes. Announcement types of articles are less, most of the articles for deeply analyzed the situation and significant number of articles has different tones with people fear, safety of the plant, security measures during the emergency, etc. But the same time some articles have the different views, opinions from people, plant officials too. About 20\% of articles published with pictures of the plant, people and local villages. But this time many articles are also carried out from the news agencies and own sources.

\section{News Stories related to Nuclear Energy Issues Published by the Hindu}

The Hindu, another mostly reading newspaper is also analyzed for this study. This newspaper published 9 news articles (Average 3 articles per month) during the non-peak season and 37 articles (average of 12.33 per month) during the peak season. Most of the articles published in the city, state, district pages and science \& technology (S\&T) column also and the sizes of the articles are smaller in size. The placement of the articles is also not prominent. But many articles are announcement in nature, those are supplied by the plant officials and some are neutral. There is no negative tone in the news. Rarely the articles are published with pictures. Mostly they used their own source. In the peak season, the scenario is different. The number of articles is high and many of them occupied in the main page and S\&T column, remaining articles are placed in the city, state, nation and district pages. The size of the articles is also larger than non-peak season with prominent space. Announcement type of articles is less; analysis with negative/neutral tone is high. Most of the articles come out with pictures. Many articles are carried out from own source as well as news agency.

\section{Opinion of the Experts}

In-depth interview was conducted with various experts related to this issue. Journalists, nuclear plant authorities, experts from nuclear science and media were interviewed. The interview also proved that the nuclear issue is a highly controversial topic in India. The researcher could not get enough number of appropriate people. Few peoples hardly open up their views, still they are requested not disclose them by name or designation, because it will 
create some problems in the organization`. Even though they are not exposed, the interviews are presented here like anonymous news reports.

Journalists say that most of the newspaper/media organizations do not have specific journalists except one or two to write these articles. Our newspapers concentrate mostly on sensitive and attractive issues like politics, economics, crime, cinema, etc. Nuclear issue is a small area; numbers of readers are less for that. If any problem arises we will concentrate on the nuclear issues. During the time of Tsunami we covered the nuclear plant news more. If the nuclear plant officials send any press releases or conducting press meet only we can cover the news. Many press releases are hard to understand and mostly in English language, not in regional language. Experts are also using difficult languages. Another one thing is getting touch with the nuclear plant officials, experts very hard. So, we are not concentrating on this. Any major accident or incident happens then we concentrate on that.

Nuclear plant authorities opined that, we have much of work. So, regular follow up on newspaper, issuing press releases, accessing to journalist is difficult. Another important thing is our officials do not know how to handle the media people. Most of the journalists have negative attitude about the nuclear issues. If we are saying something, they misunderstand some other thing. We could not reveal all information to them. If we say something it will create problem. Getting permission for speaking with media is also hard in our organization. Nuclear experts opined that, we are doing good job and keeping good relations with media. But we cannot provide all details to the journalists. Lot of technicalities, secrets is also in these issues. Many journalists cannot understand the subject even we explained to them. There are no special correspondents for dealing this type of science and technology news.

Media experts say that, there is a long gap between the media people and scientists/ scientific organizations like nuclear plants. Both sides have many deficits. Journalists are not specializing nuclear issues. The media organizations are also not concentrating nuclear issues until arising bigger problems. Allotting special reporters for the nuclear issues and providing training is very important, because nuclear plants are very important for people as well as country's development. Same time, government, related departments and nuclear plants should concentrate on this. Inviting media people only for press meet, felicitations should be avoided. Regular touch with media people, providing needy information, frequent call to 
media for visiting nuclear facility, workshops, training, etc. should be provided by the authorities. Easy accessibility of scientists, authorities to journalists are also important. This will help both the media people and nuclear plants. Peoples should be educated through media about the nuclear issues, because without people acceptance, understanding it will not succeed.

\section{Findings \& Conclusion}

Results of this research show much new information, reality about the Indian nuclear issuesmedia-public. Awareness is directly related with the access and usage of mass media, because media provides a lot of information frequently. The survey reveals that, all of the respondents are reading different dailies in Tamil and English, but mostly in Tamil. About 2/3 of respondents are aware that the nuclear energy is useful for generating electricity. Only 39\% of respondents are aware nuclear energy is also useful for medicine, technology, weapons. One fourth of the respondents felt that nuclear energy is safe. Regarding to the IndoAmerican civilian nuclear deal only $1 / 3^{\text {rd }}$ respondents are aware, while $27 \%$ just heard and $43 \%$ do not even know. Even though the public is feared about the safety of nuclear plants, $75 \%$ of the respondents welcome nuclear plants in India; this is a complex phenomenon, since most of the people fear and the same time they are welcome the nuclear energy. May be the reason behind that nuclear energy can boost industries and provides more employment. Hence, they are insisting more safety measures at the nuclear plants. Half of the respondents feel frightened in living around nuclear energy plant but one fourth of respondents feel comfortable and safe respectively. More than half of the respondents are not aware of protection arrangements in nuclear energy plant. Just one fifth of respondents are only aware of protection arrangements in nuclear energy plant or its radiation effects.

Regarding to the newspapers and the nuclear energy news coverage, there is an accusation that there is not much news coverage. One fifth said that they do not get enough information about the nuclear issues, while small percentage felt that they are confused after reading the news articles. $22 \%$ of respondents said that after reading the news they are getting the sense of fear. A majority of respondents felt that more articles should be published about the nuclear energy in simple and understandable manner with pictures will be more added values. They also said that proper visibility and space is a pre-request; use of more scientific terminology is a barrier for nuclear energy news. Half of the respondents says that they 
believe/trust the news published by the newspapers during any emergency or crisis situation regarding to nuclear energy, but about $44 \%$ says that they believe the word of mouth from any officials, friends and neighbors and they don't believe news. It is an important issue for the newspapers. Unbiased information which is clear to understand, making use of graph/pictures is essential part of news article coverage to make it meaningful purpose. Quoting with the trustworthy persons from the atomic plants, specialization is also needed for these issues.

From the content analysis, it is found that newspapers have published less number of news items. The newspapers are not giving more concentration on nuclear issues unless otherwise any emergency arises. The newspapers have published less number of news items on nuclear issues during the non-peak season and more in peak-season that is after the Fukushima nuclear accident in Japan. In the non-peak season all the articles placed in the district, state pages without any pictures and the major source of the news is press release. But during the peak season this trend is completely changed. Significant numbers of articles are published in the main page and number of articles is also more. The size and placement of the news got some more importance. They published articles about the dangers of the nuclear plants, radiation and fear of the public. Some of the articles have pictures; hence they are more attractive and got importance.

From the in-depth interview, journalists opined that, most of the newspapers do not have special reporters to write these articles. Nuclear issues have fewer readers. If any problem arises we will concentrate. Mostly we depend on press releases or press meets. Many press releases are hard to understand and mostly in English language with many jargons. Experts are also using technical language. Getting touch with the nuclear plant officials, experts are tough. Nuclear plant authorities speak out that regular follow up on newspapers, issuing press releases, always accessing to journalist is difficult. Most of the journalists are in negative attitude about the nuclear issues. If we are saying something, they misunderstand some other thing. Media Experts argues that there is a long gap between the media-scientists-scientific organizations. Both sides have many deficits. Journalists are not specializing nuclear issues and they are not concentrating nuclear issues until arising bigger problems. Allotting special reporters for the nuclear issues and providing training is very important. Governments, related departments and nuclear plants should take more concentration on this. Regular touch 
with media people, providing needy information, frequent call to media for visiting nuclear facility, workshops, training, etc. should be provided by the authorities. Easy accessibility of scientists, authorities to journalists is also important. These will help both the media people and nuclear plants. Peoples should be educated through media about the nuclear issues, because without people acceptance, understanding it will not succeed. 


\section{References}

Abalkina, I., \& Melikhova, E. (2006). Barriers to Effective Public Communication on Nuclear Issues in Russia. Nuclear Safety Institute, Russian Academy of Sciences (IBRAERAS), http://www.euronuclear.org/events/pime/pime2006/presentations/ Abalkina_paper.pdf.

Arulchelvan, S. (2010). Science and Technology Content in Indian Newspapers: A Critique. Mass Communicator - International Journal of Communication Studies , 4 (3), 32 40 .

Bagla, P. (n.d.). Inside India's Largest Nuclear Plant. NDTV, http://www.ndtv.com/news/india/ndtv_exclusive_inside_indias_largest_nuclear_pla nt.php .

Balaji. (2010, January 11). Inside India's Largest Nuclear Plant. Retrieved from http://www.ndtv.com/news/india/ndtv_exclusive_inside_indias_largest_nuclear_pla nt.php .

Barton, C. (2011). The Nuclear Experts and the Canadian Media. http://nucleargreen.blogspot.com/2011/03/nuclear-energy-experts-andcanadian.html. .

Beatty, R. A. (1997). Facts About Applying Nuclear Technology to generate Electricity. http://www.sustainablenuclear.org/PADs/pad9708beatty.html. Centre for reactor Information (CFRI).

Beatty, R. A. (2009). The Nuclear Renaissance, What Makes Now the Right Time, 33 Arguements. http://www.sustainablenuclear.org/PADs/pad9708beatty.html. Center for Reactor Information (CFRI).

Bell, L. (2010). Media Hype Over Nuclear Energy Increases Anxiety and Confusion. http://www.forbes.com/sites/larrybell/2011/04/12/media-hype-over-nuclear-energyincreases-anxiety-and-confusion/.

Berry, L., Jones, A., \& Energys, T. (1999). Media Interaction with the Public in Emergency Situations: Four Case Studies, A Report Perpared by under an Interagency Agreement by the Federal Research Division, Library of Congress.

Bisconti, A. S. (2006). Growing Public Awareness Enhances Nuclear Energy's Image, Perspective Opinion on Public. Bisconti Research Inc., Nuclear Energy Institute. 
Boyar, R. E. (1997). Radiation and Common Sense. ),

http://www.sustainablenuclear.org/PADs/pad9709boyar.html. Center for Reactor Information (CFRI).

Boyar, R. E. (2010). Risk, Safety and the Average Man. Centre for Reactor Information (CFRI).

Charman, K. (2001). Nuclear Energy Gets Media Makeover Energy Crisis Sparks Atomic Hype. http://www.fair.org/index.php?page=1069: Fairness \& Accuracy in Reporting (FAIR).

Deolalikar, R. (2008). Safety in Nuclear Energy Plants in India. Indian Journal of Occupational \& Environmental Medicine, 12(3), 122-27.

Dewhurst, P. (2011). Nuclear Setbacks Demand Stronger Communication. Frontline Online, International Public Relations Association, http://www.ipra.org/frontlinedetail.asp?articleid=2231.

Dutton, J. (1997). The World Relies on Nuclear Energy and Must Sharply Expand the Future Nuclear Role. http://www.sustainablenuclear.org/PADs/pad9504dutton.html. Centre for Reactor Information (CFRI).

Fischhoff, B. (2009). The Nuclear Energy Industry's Communication Problem. The Bulletin, http://www.thebulletin.org/web-edition/features/the-nuclear-energyindustrys-communication-problem.

Frost, B. (2005). The Promise of Nuclear Energy. http://sustainablenuclear.org/PADs/pad0509frost.html. Center for Reactor Information (CFRI).

Graham, T. W. (2010). The Pattern and Importance of Public Knowledge in the Nuclear Age. The Journal of Conflict Resolution, http://jcr.sagepub.com/content/32/2/319.

Jones, D. (2011). Media Report: Nuclear Energy After Fukushima - Presentation Transcript. http://www.slideshare.net/DowJonesInsight/media-report-nuclearenergy-after-fukushima.

Joseph, L. (2011). The SeeSaw Media Coverage of Japan's Nuclear Crisis. Belfer Centre for Science and International Affairs, Harvard Kennedy School, http://belfercenter.ksg.harvard.edu/publication/20903/seesaw_media_coverage_of_j apans_nuclear_crisis.html. .

Kincaid, C. (2005). The Media and Nuclear Energy. http://www.aim.org/mediamonitor/the-media-and-nuclear-energy. 
Marsh, G. E., \& Stanford, G. S. (2006, Nov/Dec.). How To Spread Nuclear Energy without Sharing Nuclear Know-How. Bulleting of the Atomic Scientists, p. www.thebulletin.org.

Moore, P. (2009). Media Coverage that Doesn't Disclose Moore's Nuclear Consultancy Work. Source Watch, , http://nuclear-news.net/information/media/.

NAS. (1956). Report to the Public - The Biological Effect of Atomic Radiation. Washington: National Academy os Sciences - National Research Council.

NPT. (May, 1995). Non-Proliferation Treaty Review Conference. http://www.nuclearfiles.org/menu/library/treaties/non-proliferationtreaty/reviewconf/trty_npt_reviewconf-1995-main-com-3_1995-05-05.htm.

NuclearPerception. (2011). Nuclear Energy. NC State University, https://sites.google.com/a/ncsu.edu/nuclear-energy/public-perception.

Olds, F. C. (1997). Our Unique electric Society. http://www.sustainablenuclear.org/PADs/pad9607boyar.html. Centre for Reactor Information (CFRI).

Perko, T. (2011). Importance of Risk Communication During and After a Nuclear Accident. Integrated Environmental Assesment and Management, SETAC, 7(3), 388-392.

Ramamurthy, K. (February 26, 2009). Nuclear Energy is Safe. The Hindu, p. http://www.hindu.com/2009/02/26/stories/2009022657520600.htm.

Ropeik, D. (2011). Poor Risk Communication in Japan is Making the Risk Much Worse. http://blogs.scientificamerican.com/guest-blog/2011/03/21/poor-risk-communication -in-japan-is-making-the-risk-much-worse/.

Singh, O. P. (2009). Nuclear Awareness Festival. The Hindu, p. http://www.thehindu.com/2009/02/26/stories/2009022658140200.htm .

Smith, N. (1983). Energy Coverage, Media Panic: An International Perspective. New York.

Srinivasan. (2009, February 26). Nuclear Energy is Safe: Scientists. The Hindu, p. http://www.hindu.com/2009/02/26/stories/2009022657520600.htm.

TheHindu. (February 26, 2009). Nuclear Energy is Safe. Madurai.

TheHindu. (n.d.). Nuclear Awareness Festival. http://www.thehindu.com/2009/02/26/stories/2009022658140200.htm .

Van, B. (n.d.). Media and Nuclear Energy: How Did the Media Perform? Retrieved from http://www.scribd.com/doc/113714/essay-on-media-and-nuclear-energy. 
Voiland, E. E. (2003). Did You Know That...? - Facts about Energy.

http://www.sustainablenuclear.org/PADs/ pad0309voiland.html. Centre for Reactor Informations (CFRI). 